\title{
Las Madres de Plaza de Mayo \\ EN EL AMANECER DE LA DEMOCRACIA: \\ SOBRE LA REAFIRMACIÓN DE LA EXIGENCIA DE «APARICIÓN CON VIDA»
}

The Mothers of the Plaza de Mayo at the Awakening of Democracy: On the Re-Assertion of the «Appearance Alive» Request

\section{María Virginia Morales \\ Universidad Nacional de Villa María (UNVM) - Consejo Nacional de Investigaciones Científicas y Tecnológicas (CONICET) - Progra- ma de Estudios en Teoría Política (CIECS-CONICET)}

RESUMEN: Este artículo se sitúa en el contexto argentino de retorno de la democracia, con la finalidad de analizar el modo mediante el cual las Madres de Plaza de Mayo intervienen en las disputas por significar tanto al pasado reciente de horror como a la emergente configuración social. Nos detendremos en esta intervención a partir de la acción del colectivo de reiterar la exigencia de «aparición con vida» en el nuevo contexto constitucional. En este sentido, inspirados en la perspectiva de la Teoría del Discurso Político desarrollada por Ernesto Laclau y Chantal Mouffe, proponemos indagar en la reafirmación de esta exigencia conformada durante la resistencia y oposición al gobierno de facto mediante el análisis de los sentidos que se articulan en ella, previa reconstrucción de las condiciones que habilitaron y condicionaron su reafirmación en dicho contexto.

Palabras clave: Madres de Plaza de Mayo, democracia, vida, justicia, impunidad.

RESUM: L'article se situa en el context argentí de retorn de la democràcia, amb la finalitat d'analitzar la manera en la qual les Madres de Plaza de Mayo intervenen en les disputes per a significar tant el passat recent d'horror com l'emergent configuració social. Ens aturarem en aquesta intervenció a partir de l'acció del col·lectiu de reiterar l'exigència d'«aparició amb vida» en el nou context constitucional. En aquest sentit, inspirats en la perspectiva de la 
teoria del discurs polític, desenvolupada per Ernesto Laclau i Chantal Mouffe, proposarem d'indagar en la reafirmació d'aquesta exigència conformada durant la resistència i oposició al govern de facto mitjançant l'anàlisi dels sentits que s'hi articulen, prèvia reconstrucció de les condicions que van habilitar i van condicionar-ne la reafirmació en aqueix context.

Paraules clau: Madres de Plaza de Mayo, democràcia, vida, justícia, impunitat.

ABSTRACT: This article addresses the return-to-democracy context in Argentina after the civil-military dictatorship in order to analyse the Mothers of the Plaza de Mayo interventions in the disputes to make sense of both the dreadful recent past and the emerging social configuration. We focus on the «appearance alive» request in the new constitutional context. Thus, drawing on Political Discourse Theory jointly developed by Ernesto Laclau and Chantal Mouffe, we examine this request which began during the «de-facto» government days by analyzing the multiple meanings attached to it while we re-construct the enabling and constraining conditions involved in the new constitutional context.

KeYWORDs: Mothers of the Plaza de Mayo, democracy, life, justice, impunity.

\section{Introducción}

$A_{\text {dente electo Raúl Alfonsín y con ello retorna la democracia al país luego }}^{\text {rgentina, } 10 \text { de diciembre de } 1983 \text {. Asume al Poder Ejecutivo el presi- }}$ de una de las dictaduras cívico-militares más cruentas de toda Latinoamérica. Con 30000 desaparecidos, centenares de centros clandestinos de detención y torturas, presos políticos y una resistencia al gobierno militar protagonizada por el Movimiento de Derechos Humanos (MDHS) en la que convergieron las principales fuerzas políticas y sociales nacionales, la emergente democracia se constituiría no sólo en una salida del horror, sino también en la superficie de inscripción de múltiples demandas y expectativas. 
Dentro del MDH, la confrontación con el Gobierno militar que establecieron las Madres de Plaza de Mayo ${ }^{1}$ (MPM) cobró una relevancia inusitada durante los últimos años de dictadura. La lucha por sus hijos detenidos-desaparecidos trascendió a nivel internacional, mientras que en el ámbito nacional encabezaron todas las manifestaciones de repudio a la dictadura, alcanzaron un masivo apoyo ciudadano y sus demandas se constituyeron en un espacio de confluencia con múltiples sectores. En esta confrontación jugó un rol central la exigencia de «aparición con vida» y los procesos articulatorios que acontecieron en torno a ella. Lo importante para este artículo reside en que una vez restablecido el Estado de Derecho, las MPM confrontaron con el nuevo Gobierno mediante la reafirmación de esta exigencia junto con la de «juicio y castigo a los culpables». Ahora bien, ¿por qué reiterar y reafirmar estas demandas conformadas durante la dictadura en el contexto democrático? ¿Por qué demandar «aparición con vida» luego de comprobado que no existían desaparecidos con vida en la Argentina en el amanecer de la democracia?

Dentro de las múltiples investigaciones sociales que analizan a las MPM, se destacan aquellas que indagan en la emergencia de su lucha en dictadura y su devenir durante los primeros años de la democracia. Estas últimas, en su mayor parte, giran en torno al posicionamiento que adoptaron las MPM ante el Gobierno constitucional destacando una radicalización de su lucha desde la que fundamentan la pérdida de protagonismo del organismo y la emergencia de un discurso antidemocrático (D’Alessandro, 1998; Leis, 1989; Pereyra, 2005): A partir de dos puntos se analiza dicha radicalización, primero, la reafirmación en democracia de la exigencia de «aparición con vida» emergente

1. El Gobierno militar implementó una serie de metodologías represivas como detenciones ilegales, torturas, asesinatos y desapariciones de personas. En un clima de silencio respecto de estas metodologías, muchas madres emprendieron la búsqueda de sus hijos desaparecidos por diversas instituciones. En sus recorridos diarios, no sólo no recibieron respuestas respecto de lo acontecido con ellos, sino que se encontraban cada día con un número mayor de madres en la misma situación, de modo tal que de sus encuentros en la búsqueda individual comenzaron a emerger sentimientos de solidaridad, contención e igualdad entre estas madres. Luego de múltiples fracasos solitarios de búsqueda, decidieron concurrir a la plaza de Mayo el 30-05-1977 para redactar una carta al presidente de facto con la pregunta respecto de lo ocurrido con sus hijos. De este modo se conforma el proceso de emergencia de las Madres de Plaza de Mayo y de búsqueda colectiva de sus desaparecidos. Véase Bellucci, 2000; Gorini, 2006; Morales, 2010. 
durante el horror y, segundo, las nuevas relaciones que establecen las MPM con sectores militantes de izquierda.

En relación a lo dicho, e inspirados en la perspectiva de la Teoría del Discurso Político desarrollada por Ernesto Laclau y Chantal Mouffe (1985; 1993; 1990), nos proponemos analizar la operación que implicó la reafirmación de la exigencia de «aparición con vida» con la finalidad de problematizar aquellas interpretaciones que frecuentemente consideran la imposibilidad lógica de este enunciado al ser pronunciado en un contexto en el que no existían desaparecidos con vida en el país. Para ello, en primer lugar nos detendremos en la emergente configuración democrática y en particular en cómo se articuló en ella la problemática de las violaciones a los derechos humanos en el pasado reciente. Así, luego de reconstruir el contexto que habilitó y condicionó dicha reafirmación, en un segundo momento indagaremos en los sentidos que se articulan en esta demanda y en la nueva etapa de lucha que abrirá la asunción del nuevo presidente para las MPM. Al finalizar el escrito, habremos analizado la manera en que las MPM intervienen en la disputa por significar tanto al pasado de horror como a la emergente democracia a partir de la reiteración de la consigna «aparición con vida» en el nuevo contexto constitucional.

\section{Democracia, vida y derechos humanos}

La perspectiva analítica desarrollada por Ernesto Laclau y Chantal Mouffe, nos permite realizar una lectura sobre el desarrollo de las MPM en el periodo en cuestión problematizando aquellas interpretaciones de corte principalmente histórico y sociológico que consideran que la radicalización de la lucha del organismo durante los primeros años de democracia lleva implícito el avance de un discurso antidemocrático dentro del mismo. ${ }^{2}$ En particular, una serie de conceptos de esta perspectiva nos habilitan a indagar en aspectos que han sido mayormente subestimados u olvidados por dichas investigaciones y que en

2. Consideramos relevante volver sobre esta consideración en tanto no sólo proliferó en ámbitos académicos hacia fines de los años ochenta, sino que también adquirió fuerza con el transcurrir de la década entre las fuerzas sociopolíticas dominantes del país, el periodismo y la opinión pública. 
estas páginas consideramos de suma relevancia para comprender el modo en que la lucha de las MPM se reconfigura en este momento. Así, desplazando la mirada hacia una concepción discursiva de lo social y las identidades, en donde la negatividad y el antagonismo adquieren un carácter constitutivo, nos proponemos repensar la nueva etapa de lucha contra la impunidad que se conforma producto del rechazo que protagonizan las MPM a las políticas oficiales en torno a la problemática de los detenidos-desaparecidos poniendo el acento en las rearticulaciones de sentidos que se producen al interior de su discurso.

La perspectiva analítica en la que se inscribe este artículo parte de tres supuestos que devienen centrales para abordar nuestros objetivos. En primer lugar, la concepción discursiva de lo social. En términos de la Teoría del Discurso Político, todo objeto y toda práctica tiene un significado, siendo el mismo establecido en un sistema de relaciones constituidas socialmente. Con lo cual, los objetos y las prácticas adquieren su significado e identidad de manera relacional, contextual y contingente. A este sistema de relaciones los autores lo denominan «discurso» (Laclau y Mouffe, 1990): Por consiguiente, concebir a lo social como un espacio discursivo, pone de manifiesto «el hecho de que toda configuración social es una configuración significativa» (Laclau, 1990, p.114); una totalidad estructurada de modo parcial y precario que no está sustentada en ninguna relación de necesidad, sino que se instituye políticamente por medio de discursos que dan sentido al orden social.

Ahora bien, esta institución nunca puede ser total ya que siempre está rodeada por un campo de la discursividad que la sobrepasa y subvierte poniendo al descubierto su radical contingencia. La institución de lo social, entonces, es el resultado de un proceso de lucha política en la que los diferentes discursos compiten por producir y fijar el sentido de lo social de modo tal que toda configuración discursiva está atravesada y constituida por relaciones de poder y antagonismo. Precisamente en este punto se define el segundo supuesto que nos interesa destacar: toda objetividad, toda constitución discursiva, es un acto de poder. En términos de Laclau:

La afirmación del carácter constitutivo [del poder] implica, según hemos visto, la afirmación de la naturaleza contingente de toda objetividad y esto presupone, a su vez, que toda objetividad es una objetividad amenazada. Si a pesar de ello puede afirmarse parcialmente como objetividad, esto sólo puede darse sobre la base de reprimir aquello que la amenaza (Laclau, 1990, p.48): 
Por consiguiente, si el poder es condición de posibilidad de toda configuración social, toda significación o identidad que tenga lugar dentro de una formación discursiva particular, no será un punto homogéneo sino un conjunto articulado de elementos. La fijación del sentido de lo social es como dijimos siempre parcial y contingente, a la vez que involucra la puesta en marcha de prácticas articulatorias a través de las cuales se establecen relaciones entre los elementos discursivos de manera tal que su identidad es modificada como resultado de estas prácticas (Laclau y Mouffe, 1985, pp.142-143): Desde esta perspectiva, toda identidad es el efecto de un contexto atravesado por relaciones de poder, con lo cual, toda identidad es una estabilización precaria y contingente que permanentemente construye y reconstruye sus propios contenidos y referentes. En pocas palabras, es su carácter abierto e incompleto el que habilita su permanente redefinición.

Sin embargo, como las prácticas y procesos de articulación a las que hacíamos referencia anteriormente no son necesarias, y siendo que ellas acontecen $\mathrm{y}$ adquieren significación a partir de relaciones de poder y antagonismo, sus estructuras, sus formas y contenidos, dependerán enteramente de aquello que niegan y excluyen. Finalmente, entonces, el carácter constitutivo de la negatividad y el antagonismo en todo proceso de constitución de los discursos y las identidades es el tercer supuesto de la perspectiva en cuestión que enfatizamos. En los párrafos siguientes analizaremos las articulaciones que otorgaron sentido a la configuración social que hegemonizó los albores de la democracia con la finalidad de detenernos en el modo en que se inscribió en ella la problemática de los derechos humanos, para luego detenernos en la reconstitución de la lucha de las MPM en una lucha contra la impunidad y en el proceso de resignificación de sentidos que implicó la reiteración de la consigna «aparición con vida» en dicha configuración social.

Como ha sido argumentado en análisis sobre el tema, el discurso de Raúl Alfonsín definido alrededor de la noción de «democracia» constituyó una frontera política que marcó una ruptura con el pasado reciente de violaciones a los derechos humanos, a la vez que articuló una enunciación crítica respecto de ese pasado. Cuestión que lo mostró dispuesto a impulsar una revisión de lo acontecido durante la dictadura bajo la promesa de que no habría impunidad 
para los crímenes cometidos en ella, al mismo tiempo que lo posicionó en una clara distancia respecto del Gobierno militar y de las prácticas violentas (Aboy Carlés 2001; Barros, M. 2009, 2011; Barros, S. 2002): En el período preelectoral, la figura del líder radical se constituyó como la única posición política capaz de dar respuesta a los reclamos de verdad y justicia del MDH.

De este modo, la democracia emergía en el discurso de Alfonsín como la condición misma de los derechos humanos y su lucha (Barros M., 2007) y como la condición misma de la vida. Al respecto, Aboy Carlés (2001) destaca que «el terrorismo de Estado asociado al régimen militar iniciado en 1976 permitió asimilar en el discurso alfonsinista la distancia entre la democracia y la dictadura como una distancia entre la vida y la muerte» (p.171): A su juicio, éste es el rasgo fundamental que define a la frontera trazada por Alfonsín. En este sentido, la consigna de campaña «Somos la vida» del Partido Unión Cívica Radical (UCR) no fue una consigna ajena a las MPM, y más en general al MDH, en tanto retoma su lucha «por la vida» y la inscribe en la noción de democracia (Jelin, 1987; González Bombal y Sonderéguer, 1987; Jelin y Azcárate, 1991):

Ahora bien, en este punto, Mercedes Barros (2009) destaca que esta reapropiación por parte de Alfonsín de la lucha del MDH y su articulación con la noción de «democracia», implicó alterar los sentidos y significados que los derechos humanos habían adquirido en la resistencia a la dictadura. Durante las primeras semanas del gobierno constitucional, las violaciones a estos derechos cometidas durante el horror ocuparon un lugar central. Al respecto, expresaba el mandatario luego de su asunción:

Las violaciones extremadamente aberrantes de los derechos que hacen a la esencia de la dignidad humana, en que incurrieran el terrorismo y la represión de ese terrorismo no pueden quedar impunes [...] La convicción de que es necesario hacer justicia con quienes, desde uno y otro lado, han tomado a los hombres como meros objetos manipulables para obtener ciertos fines, implica que debe derogarse y declararse insanablemente nula la ley de facto llamada de «pacificación»o «amnistía». (Alfonsín, 1988 b) 
Al mismo tiempo, el Poder Ejecutivo propuso la modificación del Código de Justicia Militar, ${ }^{3}$ decretó la apertura de los juicios a los responsables de la violencia y las violaciones a los derechos humanos cometidos en dictadura y ordenó la creación de la Comisión Nacional sobre Desaparición de Personas (CONADEP), que tendrá por objeto esclarecer los hechos relacionados con la desaparición de personas ocurridos en el país. Todas estas acciones adquirieron sentido y se articularon en un discurso en el que, como dijimos, la defensa de la vida estaba sujeta a la democracia y al futuro de la misma.

Producto de las mencionadas alteraciones, la violencia del pasado, las muertes y las desapariciones fueron reinterpretadas como el resultado de «la violencia espasmódica del terrorismo subversivo y de [una] represión indiscriminada con su secuencia de muertos y desaparecidos» (Alfonsín, 1988 a): Es decir, Alfonsín sería el principal enunciador de lo que se denomina «la teoría de los dos demonios». Ésta proponía una interpretación del pasado que, recogiendo ciertas representaciones sobre la violencia política y la represión que circulaban en la Argentina a mediados de la década de 1970, establecía que las violaciones a los derechos humanos debían ser entendidas en un contexto de enfrentamiento entre dos terrorismos: el de extrema izquierda y el de extrema derecha. De esta manera, el presidente sostenía:

La lucha entre sectores extremistas, así como el terrorismo de Estado, han dejado profundas heridas en la sociedad argentina. La manera de restañar esas heridas no puede girar en torno a venganzas o resentimiento [...] Pero la democracia [no] podría edificarse sobre la claudicación, actuando como si aquí no hubiera ocurrido nada. (Alfonsín, 1988 a)

Así pues, el mandatario puso en manos de la justicia la tarea de evitar la impunidad de los culpables mediante la orden de procesamiento de los líderes del Ejército Revolucionario del Pueblo (ERP) y de Montoneros, y de las cúpu-

3. Mediante ello, el gobierno remitió al interior de las Fuerzas Armadas el juzgamiento de su actuación e introdujo la obligatoriedad de apelación a un Juzgado Civil. A su vez, introdujo el principio de Obediencia Debida que sostenía que los delitos de violaciones a los derechos humanos cometidos por oficiales inferiores no deberían ser condenados penalmente por haber actuado en obediencia a las órdenes dadas por sus superiores. 
las de las tres primeras Juntas Militares. ${ }^{4}$ Todo lo cual, visibiliza una doble igualdad que definió los primeros momentos del discurso oficial. La igualdad en la responsabilidad de ambos terrorismos en el pasado de violencia y abusos (Barros, M., 2009), y la igualdad ante la ley con la que ambos deberían ser juzgados (Barros, M., 2009; Gargarella, 2010): Por lo tanto, en este nuevo contexto:

[1]a demanda por los derechos humanos era así identificada y entendida en relación a ese otro excluido, es decir en oposición a ambas formas de violencia y a toda parcialidad. Su significado estaba entonces sobredeterminado por la neutralidad/imparcialidad que suponía la democracia y sus instituciones. (Barros, M., 2009, p. 9)

Como consecuencia de ello, los desaparecidos, detenidos y muertos comenzaron a ser definidos como «víctimas inocentes» que fueron el resultado de ambas formas de violencia y abusos (Barros, M., 2009; Carnovale, 2006): Condición de inocencia que devino, para decirlo en términos de Barros, en una implícita condena social a los que no eran tan «inocentes», dejando disponible cierta justificación del tratamiento inhumano que recibieron aquellos culpables subversivos. Cuestión que, a su vez, circunscribió el reclamo en términos de derechos humanos a las víctimas que no estaban directamente involucradas a los grupos revolucionarios. Lo relevante de todo lo dicho radica en que estas alteraciones o desplazamientos de sentidos producto de la inscripción de la lucha del MDH en la nueva formación política emergente en 1983, le imprimieron nuevos usos y sentidos a los términos «vida», «derechos humanos», «víctima», «guerra», «subversión».

Así pues, analizando el discurso que hegemoniza el amanecer de la democracia, ¿de qué modo se reconstituyen las demandas de «aparición con vida» y «juicio y castigo a los culpables» en el discurso de las MPM y de qué modo estas consignas son reafirmadas en el contexto constitucional? Con estas preguntas en mente desarrollaremos el próximo apartado.

4. Véanse los decretos $157 / 83$ y $158 / 83$ 


\section{3. «Posdictadura», muerte e impunidad}

Todas las políticas en materia de derechos humanos impulsadas por el Poder Ejecutivo fueron rechazadas y discutidas por las MPM. Rechazan «los términos empleados por el Gobierno que intentan equiparar a [sus] hijos con los represores de éstos infamantes años» (MPM, 01-03-84) y que retoma aque1la lectura que las definía como madres de terroristas - una lectura que apareció con gran fuerza durante los primeros años de dictadura y que fundamentó su aislamiento inicial de la ciudadanía. Junto a la totalidad del MDH, se oponen a la modificación del Código de Justicia Militar y el principio de Obediencia Debida que el mismo sostenía. Confrontan con los términos y las condiciones de los procesos judiciales iniciados y reclaman la participación de la justicia civil y los juzgados populares en el juzgamiento de los delitos cometidos por miembros de las Fuerzas Armadas (FFAA) y de Seguridad:

Las Madres reclamamos que los militares e integrantes de los organismos de seguridad, responsables de los crímenes de lesa humanidad [...] sean juzgados con la mayor celeridad e imparcialidad. Por ello afirmamos rotundamente que no deben ser juzgados por sus pares [...] Pero sin dudas, la objeción más importante recae en [...] el principio de la "obediencia debida" [...] Es de justicia reclamar que quien arrojó una persona al mar desde un avión sea tratado como criminal al igual que quien le dio la orden para hacerlo. (MPM, octubre 1984)

A su vez, discuten los mecanismos de investigación y el tratamiento que el gobierno puso en marcha respecto de los detenidos-desaparecidos. De este modo, rechazan la creación de la CONADEP bajo la consideración de que así se investigará a las víctimas de la violencia y los abusos, pero poco se dirá respecto de los responsables de dichas atrocidades. En este sentido, se niegan a recibir huesos de cadáveres, resisten a la inhumación de tumbas y fosas con NN que arrojan como conclusión la «"muerte por enfrentamiento”, fecha, lugar y área operativa» (MPM, 16-04-1984): Confrontan con todo aquello que

5. Cabe destacar, que en los primeros meses de democracia los medios de comunicación comenzaron a dar cuenta de la represión en una magnitud mayor a lo difundido años antes. En sus relatos, reiteraban la lectura oficial respecto de la problemática de violaciones a los derechos humanos cometidos durante la dictadura, como así también el modo de interpretar el accionar de las Madres frente a las políticas gubernamentales. 
confirme o arroje certezas sobre su muerte en una operación en la que los responsables son invisibilizados. En su lugar, demandan investigar y juzgar a los responsables. Todo lo cual, en sus términos, falsea las causas del fallecimiento en tanto sus hijos fueron «detenidos en su mayoría ante testigos, en operativos realizados por las FFAA y de seguridad con ostentación y/o uso de armas con total impunidad» (MPM, 16-04-1984): En pocas palabras, rechazan la confirmación oficial de la muerte de los detenidos-desaparecidos y el discurso oficial que le otorga sentido.

Por lo tanto, será precisamente en negación a la lectura del pasado que equipara las dos formas de violencia y en oposición a la confirmación y aceptación de la muerte de sus hijos, conjuntamente con el ocultamiento de los responsables que dicha aceptación implicaba, que las exigencias de «aparición con vida» y «juicio y castigo a los responsables» constituidas en la resistencia a la dictadura serán reafirmadas en el amanecer de la democracia. Reafirmación que, como se desprende de las citas anteriores, también encontrará fundamento en el lenguaje de derechos humanos y en la imparcialidad/ neutralidad democrática que se articulan en la configuración social alfonsinista. Comenta la madre Graciela de Jeger al respecto:

Nosotras sabíamos que miles de desaparecidos habían sido en secreto asesinados o enterrados. Las exhumaciones no nos decían nada que nosotras no supiésemos [...] Con la exhumación ellos querían erradicar el problema de los desaparecidos, porque entonces no eran más desaparecidos, sólo personas muertas. Nosotras no queremos el nombre de las víctimas. Nosotras sabemos quiénes eran. Nosotras queremos el nombre de los asesinos. Nosotras queremos que nos digan lo que pasó. Ellos tienen que explicarnos lo que no quieren explicarnos. Éste es el sentido de la «Aparición con Vida». (Graciela de Jeger citada en Gogol, 2007, p.295)

De este modo, el fuerte rechazo a la CONADEP que protagonizaron las MPM se comprende en la reafirmación de esta exigencia. En sus términos, la investigación de la CONADEP hace pensable a la muerte como destino último de los detenidos-desaparecidos. La describe, la acepta y la confirma al mismo tiempo que olvida los nombres de los represores y oculta sus responsabilidades. En este sentido, consideran: 
Las Madres reclaman aparición con vida de los detenidos-desaparecidos y un informe detallado sobre quiénes actuaron en la época de la represión, que el pueblo se entere pero no en forma sensacionalista, sino informando quién ordenó el asesinato, quién las exhumaciones clandestinas, qué médico firmó el parte y qué juez estaba actuando. (Boletín Informativo CONADEP No 14, 1984, p.8)

Ahora bien, de estos rechazos y oposiciones a las políticas oficiales emergió una lectura respecto del Gobierno, y más en general, del orden constitucional y democrático emergente en 1983, que comenzó a poner en duda la ruptura que decía encarnar Alfonsín. Esto es, en términos de las MPM el aparato represivo no había sido desmantelado, las amenazas a madres y demás miembros del MDH se reiteraban con frecuencia y la violencia permanecía en el orden constitucional. Además, no hubo información pública sobre el destino de los detenidos-desaparecidos por las FFAA. No se conoce la documentación que al respecto guarda esa institución. No se encuentran detenidos los responsables. Los jueces que actuaron durante la dictadura han sido confirmados en sus cargos, con lo cual «la justicia es la misma y cómplice de la dictadura» (Boletín Informativo MPM No 19/20, 1984, p.16): Así, en los albores de la democracia, sostienen:

Nos encontramos a un año de Gobierno Constitucional, sin haber resuelto el gravísimo problema de los detenidos-desaparecidos. Este motivo nos impulsa [...] en busca de una respuesta a la aparición con vida y el juicio y castigo a los culpables que han cometido los crímenes más atroces que conociera nuestro país. (MPM, 28-11-1984)

De este modo, las expectativas preelectorales quedan desvanecidas. En sus palabras: «Alfonsín alcanzó el gobierno pero los militares mantienen el poder» (Boletines Informativos MPM No 18 y 19/20, 1984): Entonces, «aparición con vida» implica una lucha por verdad y justicia; una lucha que se constituye en rechazo y oposición a la persistencia del aparato represivo en el orden constitucional, a la no aceptación de la muerte y a la no aceptación de la impunidad que atraviesa el orden en el que viven. En este sentido, en un documento presentado ante la Federación de Familiares de Detenidos-desaparecidos, expresaban: 
Madres cree importante destacar la similitud entre los gobiernos posdictadura de Bolivia, Perú, países hermanos junto con Argentina. Estos gobiernos acceden por elección popular, pero mantienen las estructuras de las FFAA bajo aparente democracia, que sólo permite expresarse en la calle sin poder acceder a los medios de información. Se defiende la impunidad de los crímenes cometidos bajo leyes que juegan o simulan ser ejemplares [...] Las FFAA mantienen sus estructuras y manejan el poder que les permite sostener sus privilegios y el sometimiento del que por etapas y a medida que se recupera insiste en exigir sus derechos. (MPM, 19-11-1984)

Por lo tanto, «aparición con vida» es una exigencia que interviene sobre las relaciones de poder que hegemonizaron el horror, a la vez que denuncia su desplazamiento hacia el orden constitucional. La reafirmación de esta demanda en el nuevo orden visibiliza la persistencia — redefinida, por ciertode la experiencia dictatorial, de sus responsables, de muchos de sus términos y accionares en el entramado institucional del Estado. La consigna trae al espacio público las formas por las cuales diversas prácticas del horror se reiteran en el nuevo orden. Así, la resistencia a la dictadura que protagonizaron las MPM no se circunscribe a la sola disputa por cómo significar ese pasado, sino que también implica la disputa por cómo se construye la democracia, por el rol de los poderes del Estado y de los actores sociales y políticos. «Aparición con vida» es una demanda que pretende intervenir sobre la constitución de la nueva configuración social. Reconoce un quiebre en las elecciones de octubre de 1983, pero destaca la presencia del pasado en el presente, cuestión que imposibilita, según la perspectiva de las MPM, la constitución de un orden democrático.

En estrecha relación con lo dicho, la demanda de «juicio y castigo a los culpables» es reafirmada en negación y oposición a una justicia circunscripta al principio de Obediencia Debida, a la reforma del Código de Justicia Militar, a los procesamientos «ejemplares» ${ }^{6} \mathrm{y}$ a la inexistencia de investigaciones de los responsables del horror. De este modo, estas demandas reiteradas en

6. Véase Alfonsín, 2009, p.45. 
esta configuración alfonsinista, reconstituyen a la lucha de las MPM en una lucha contra la impunidad:

Nosotras creemos que pedir juicio y castigo y decir NO a la amnistía es la única manera de alcanzar la democracia y de vivir en paz. Sin juicio y castigo y con una amnistía encubierta, con el aparato represivo intacto, no habrá paz, ni habrá democracia, ni habrá libertad en esta Argentina. (Hebe de Bonafini, 21-12-1984)

La justicia emerge en su lucha contra la impunidad como la condición misma de la democracia, de la paz y de la libertad. Por lo tanto, la justicia adquiere en el discurso de las MPM un sentido fundacional de la democracia, al mismo momento que enuncia una demanda de ruptura institucional con etapas anteriores (Palermo, 1987): Un carácter fundacional y una demanda de ruptura institucional que disputa con el discurso oficial que posiciona a la democracia como la posibilidad de la vida, la justicia, los derechos y la libertad.

Ahora bien, como respuesta a la confrontación que establecen las MPM con el Gobierno nacional, en diferentes exposiciones públicas el presidente consideró que ellas «tienen un objetivo político que no coincide con los intereses nacionales» (Clarín, 16-12-1984, p.4): Además, reiteró que no existen desaparecidos con vida en el país y consideró necesario «que se avance como se avanzó muchísimo este año en el campo de la reconciliación de los argentinos [sin que] se confunda la justicia con la venganza» (Clarín, 16-12-1984, p.4): Así, las MPM emergen en el discurso alfonsinista posicionadas en un lugar de amenaza y desestabilización del orden constitucional. Con lo cual, «antinacionales» y «antidemocráticas» fueron los calificativos que comenzaron a sonar con mayor eco en el país para nombrarlas y para responder a cada uno de sus rechazos y confrontaciones. ${ }^{7}$ A partir de estas nominaciones y de los cuestionamientos que recibieron por parte del Gobierno y de diversos secto-

7. Expresó Alfonsín: «nosotros estamos contra todo tipo de violencia, no solamente la violencia del terrorismo de Estado sino también contra esa otra concepción elitista que pretendió, a través del terrorismo la toma del poder. Y el día que las Madres se manifiesten claramente contra esa concepción entonces podemos decir que están en la democracia» (La Prensa, 17-09-1985, p.10). 
res políticos y sociales por la radicalidad de sus demandas y por el nivel de confrontación establecida, la madre Mercedes Moreno explica respecto del sentido de reafirmar «aparición con vida»:

Ellos me arrebataron a mi hija cuando estaba con sus hijos. Yo les pregunté a mis nietos, «¿Ustedes los vieron llevarse a su mamá viva?» «Sí», me respondieron. Y les dije, «si ustedes vieron que ella estaba viva, yo la estoy buscando viva, porque si no lo está, quiero saber quién la mató y quiero al asesino puesto en la cárcel. Si yo la busco como cadáver, entonces la estoy matando yo, y no a quien la asesinó». Si mis nietos pueden entender esto, un adulto también. (Mercedes Moreno citada en Gogol, 2007, p.295)

De este modo, los rechazos de las MPM a las políticas oficiales respecto de la problemática de los detenidos-desaparecidos, y la confrontación que ello constituyó con el Gobierno nacional, a la vez que conformó su lucha en un espacio en el que la resistencia llevada adelante durante la dictadura continúa, generó una progresiva pérdida de convocatoria y capacidad de articulación con múltiples sectores políticos y sociales dominantes. Así, la reafirmación de «aparición con vida» en el nuevo contexto, devino en progresivos procesos de desarticulación, deslegitimación, desprestigio y aislamiento del colectivo. ${ }^{8}$

\section{Palabras finales}

A partir de una concepción discursiva de lo social, en donde el poder y el antagonismo adquieren un carácter constitutivo y las identidades se constituyen de modo relacional y diferencial, nos detuvimos en este artículo en el análisis del modo en que la lucha de las MPM se reconstituye en una lucha contra la impunidad que resiste a la lectura oficial del pasado reciente y a las políticas de derechos humanos implementadas en democracia. En este sentido, enfatizamos en el proceso de resignificación de sentidos que implicó la reiteración de la consigna «aparición con vida» en el nuevo contexto emer-

8. En ese momento, además, producto de nuevas articulaciones con sectores militantes de izquierda, emerge en el discurso de las MPM la consideración de que sus hijos fueron «opositores políticos a la dictadura» y en ello residió la causa de su desaparición. Como establecimos al inicio del artículo, analizar esto excede nuestros objetivos. 
gente en diciembre de 1983 y en las diferentes operaciones mediante las cuales los términos de la lucha del organismo se conformaron en negación a la hegemonía alfonsinista y a partir de la emergente lectura que establece continuidades entre el horror y la democracia en el país. En relación a ello, consideramos que las Madres apelan al término "post-dictadura» para describir el contexto de ese entonces y que su lucha no se erige en confrontación con la democracia en sí misma como sistema de gobierno y organización social como frecuentemente se ha interpretado, sino con la forma que la misma adopta en el contexto analizado. De este modo, esperamos haber argumentado que la reafirmación de «aparición con vida» en los primeros años del gobierno alfonsinista no implica la enunciación de una demanda literal, sino que más bien, da cuenta de un proceso de desplazamiento de su lucha que se define a partir de la negación de la aceptación oficial de la muerte de sus hijos que los inscribe en la «teoría de los dos demonios» e invisibiliza a los responsables. Es precisamente por ello que la figura que nomina a «los 30000» es la de «detenido-desaparecido». $\mathrm{Y}$ es precisamente por ello que reflexionar sobre las disputas por significar el pasado de horror en la Argentina a partir del proceso de reafirmación de la exigencia de «aparición con vida» que las MPM llevan adelante en el amanecer de la democracia implica detenernos en una de las tensiones que atravesarán las luchas por «memoria, verdad y justicia» desde aquel entonces hasta nuestros días.

\section{Referencias}

\section{Bibliografía}

Aboy CARLés, G. (2001): Las dos fronteras de la democracia argentina. La reformulación de las identidades políticas de Alfonsín a Menem, Homo Sapiens, Buenos Aires.

Alfonsín, R. (2009): Memoria política. Transición a la democracia y derechos humanos, Fondo de Cultura Económica, Buenos Aires.

Barros, M. (2009): «Democracia y Derechos Humanos: dos formas de articulación política en Argentina»,e-l@tina. Revista electrónica de estudios latinoamericanos, 8, 3-18. 
Barros, S. (2002): Orden, democracia y estabilidad. Discurso y política en la Argentina entre 1976 y 1991, Alción, Córdoba.

Borland, E. (2006): «Las Madres de Plaza de Mayo en la era neoliberal: ampliando objetivos para unir el pasado, el presente y el futuro», Colombia Internacional, 63, 128-147.

Carnovale, V. (2006): Memorias, espacio público y Estado: la construcción del Museo de la Memoria. Estudios AHILA en Historia Latinoamericana. Disponible en: $<$ http://riehr.com.ar/archivos/Investigacion/Carnovale $\% 20-20$ Museo $\% 20 \mathrm{de} \% 201 \mathrm{a} \% 20$ ESMA.pdf $>$.

D’Alessandro, M. (1998): «Los movimientos sociales en la transición democrática. El caso de las Madres de Plaza de Mayo: sentimiento y discurs», América Latina Hoy, 20, 41-45.

Gargarella, R. (2010): «Democracia y derechos en los años de Alfonsín», en R. Gargarella; M. Murillo; M. Pecheny (Comps.): Discutir Alfonsín, Siglo XXI, Buenos Aires, pp. 32-40.

Gogol, E. (2007): El concepto del «otro» en la liberación latinoamericana. La fusión del pensamiento filosófico emancipados y las revueltas sociales, Herramienta, Buenos Aires.

González Bombal, I. Y Sondereguer, M. (1987): «Derechos humanos y democracia», en E. Jelin (comp.): Movimientos sociales y democracia emergente/1, Centro Editor de América Latina, Buenos Aires, pp. 85-112.

JELIN, E. (comp.) (1987 a): Movimientos sociales y democracia emergente/1, Centro Editor de América Latina, Buenos Aires.

Jelin, E. Y Azcárate, P. (1991): «Memoria y política: movimientos de Derechos Humanos y constitución democrática», América Latina Hoy, 1, pp. 29-38.

LAClAU, E. (2000): Nuevas reflexiones sobre la revolución de nuestro tiempo ( $2^{\mathrm{a}}$ Ed.), Nueva Visión, Buenos Aires.

- (2004): «Discurso», Topos \& Tropos, 1, 1-7.

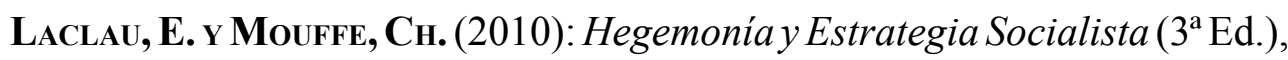
Fondo de Cultura Económica, Buenos Aires.

LeIs, H. (1989): El movimiento por los derechos humanos y la política argentina/1, Centro Editor de América Latina, Buenos Aires.

Palermo, V. (1987): «Movimientos sociales y partidos políticos: aspectos de la cuestión en la democracia emergente en la Argentina», en E. JELIN (Comp.), Movimientos sociales y democracia emergente/2 (pp. 132-175), Centro Editor de América Latina, Buenos Aires. 
Pereyra, S. (2005): «¿Cuál es el legado del movimiento de Derechos Humanos? El problema de la impunidad y los reclamos de justicia en los noventa», en F. Schuster; F. Naishtat; G. Nardacchione y S. PeREYRA (Comps): Tomar la palabra. Estudios sobre protesta social y acción colectiva en la Argentina contemporánea, Prometeo, Buenos Aires, pp. 151-191.

Fuentes citadas

Alfonsín, R. (1988 a): «Mensaje a la Honorable Asamblea Legislativa, el día 10 de diciembre de 1983», Discursos presidenciales, Secretaría de la Información Pública, Buenos Aires.

— (1988 b): «Mensaje dirigido a todo el país por radio y televisión, el día 13 de diciembre de 1983», Discursos presidenciales, Secretaría de la Información Pública, Buenos Aires.

Decreto 157/83, 13/12/1983. Disponible en: http://es.wikisource.org/wiki/Decreto $157 / 83>$.

Decreto 158/83, 13/12/1983. Disponible en: http://www.desaparecidos.org/ nuncamas/web/document/nacional/decr158.htm>.

Discurso pronunciado por Hebe de Bonafini, presidenta de la Asociación Madres de Plaza de Mayo, 21-12-1984. Disponible en AAMPM.

MPM, Comunicado de prensa, 01-03-1984. Disponible en Archivo Madres de Plaza de Mayo Línea Fundadora (AMPMLF):

MPM, Comunicado de prensa, 28-11-1984. Disponible en AMPMLF.

MPM, Gacetilla de prensa, 16-04-1984. Disponible en AMPMLF.

MPM, Boletín Informativo, Nº 14, 1984.

MPM, Boletín Informativo, No 19/20, 1984.

MPM, Documento presentado ante la Federación de Familiares de Detenidos-Desaparecidos, 19-11-1983. Disponible en Archivo Asociación Madres de Plaza de Mayo (AMPMLF)

Archivos consultados

Archivo AMPM

Archivo Diario Clarín

Archivo Diario La Prensa

Archivo MPML 